\title{
Uma metodologia de projeto de um sistema de freio de um veículo off-road: Abordagem analítica e experimental
}

\section{A Design methodology of an off-road vehicle braking system: Analytic and experimental Approach}

Rafael Fernandes Teixeira1, Ricardo Humberto Oliveira Filho², Paulo Balduíno Flabes $\mathrm{Neto}^{3}$, Vinícius Abrão da Silva Marques ${ }^{4}$, Tobias Anderson Guimarães ${ }^{5}$

\section{RESUMO}

Em um veículo off-road de competição, o sistema de freios deve garantir o travamento das 4 rodas na prova de frenagem para ser aprovado. Afim de obter o máximo de eficiência durante a frenagem, é necessário adquirir os parâmetros estáticos do veículo, desenvolver os cálculos teóricos, projetar e selecionar os componentes necessários. Com o projeto apresentado neste trabalho, o aumento na relação de alavanca do pedal, raio do disco traseiro e o desenvolvimento do projeto do balance bar permitiram reduzir a força exercida no pedal para proporcionar uma desaceleração de $0,7 \mathrm{~g}$, garantindo o travamento simultâneo dos eixos e o aumento da força de frenagem na dianteira acima de $65 \%$. O novo sistema balance bar proporcionou o ajuste da força de frenagem no eixo dianteiro, permitindo o sistema operar em terra batida e no asfalto em condições ótimas. A validação do balance bar em diferentes configurações e da pressão do sistema foi atingida em um ensaio medindo a força exercida no pedal e através de manômetros aferir as pressões nas linhas de freio, sendo possível afirmar que o novo projeto de freio atingiu o objetivo geral de confiabilidade.

Palavras-chave: Elementos de Máquinas. Engenharia Automotiva. Projeto Mecânico. Sistema de frenagem.

\section{ABSTRACT}

During the competition, the brake system of a off-road vehicle must guarantee the 4 wheels locking to be approved in the brake test. In addition, other goals have been imposed in order to achieve maximum efficiency during braking. For this purpose, it is necessary to acquire the static loads of the vehicle, to develop the theoretical calculations, to design, and to select the necessary components. The increased pedal ratio, rear disc radius and the design of the brake bias allowed the pedal force to be reduced to transmit a $0.7 \mathrm{~g}$ deceleration. Also, reached simultaneous locking of the axles, and increased braking force at the front axle above $65 \%$. The new brake bias provided braking force adjustment on the front axle, allowing the system to operate even out of road as asphalt under optimum conditions. The validation of the brake bias for different configurations and the system pressure was reached in an experiment by measuring the force on the pedal and using manometers to check the pressures in the brake lines. It is possible to affirm that the new brake design reached the main goals of reliability.

Keywords: Automotive engineering. Braking system. Mechanical design. Machine elements.

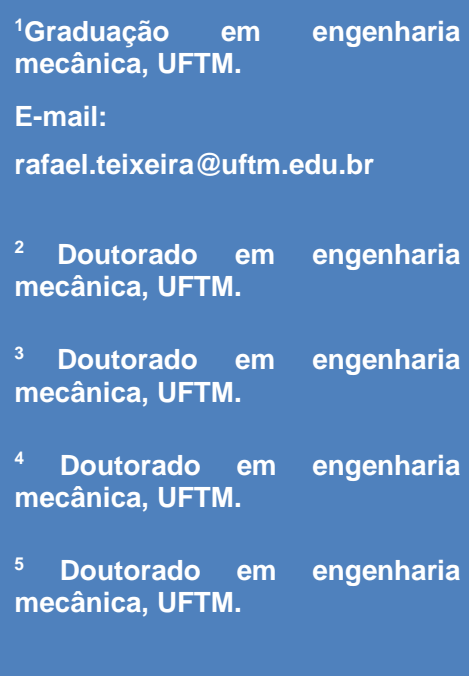

${ }^{1}$ Graduação em mecânica, UFTM.

E-mail:

rafael.teixeira@uftm.edu.br

engenharia engenharia engenharia

- 


\section{INTRODUÇAOO}

O sistema de freios tem como função reduzir a velocidade ou parar completamente o veículo, portanto está diretamente ligado à segurança do piloto e passageiros. Em uma situação de emergência o sistema deve ser capaz de converter a energia cinética em energia térmica suficiente para realizar a parada através do atrito entre o disco e a pastilha (CANALE, 1989). Em veículos convencionais, existe uma série de normas técnicas e legislações que regem as condições mínimas de um projeto do sistema de freio (NICOLAZZI, LEAL e ROSA, 2012). Para o caso de um veículo off-road de competição que deve seguir o regulamento técnico, a condição mínima para que seja aprovado na prova de frenagem é que o sistema de freios deve ser capaz de travar as quatro rodas, tanto em condição estática ou em movimento, deve ser atuado por um único pé e acionado por um sistema hidráulico.

Durante a frenagem, o peso nas rodas dianteiras torna-se maior devido ao fenômeno chamado transferência de carga do eixo traseiro para o eixo dianteiro, quanto mais brusca a frenagem, mais carga será transferida (CANALE, 1989). Vale destacar uma frase de Campbell (1970): "não importa a força aplicada nas sapatas dos freios, não interessa quanto se pode manter os tambores de freio frios, a limitação final da taxa de desaceleração é a aderência dos pneus sobre a superfície da pista". Em outras palavras, a máxima eficiência de frenagem é adquirida quando a desaceleração se iguala ao atrito da pista, com o objetivo de obter a maior eficiência possível e evitar o travamento do eixo do veículo. Para tanto, é necessário um sistema que faça a regulagem ou a distribuição da força de frenagem, pois devido à transferência de carga, o eixo dianteiro necessita de maior força de frenagem que o eixo traseiro.

Um dos sistemas comumente empregados para o controle da distribuição da força de frenagem é o balance bar. Neste componente, o ajuste da distribuição da força de frenagem é realizado rosqueando o eixo para o lado que se deseja maior força de frenagem, com isso é possível avaliar para qual relação ocorrerá o travamento simultâneo dos eixos (QUEIROZ e MENEZES, 2014). Limpert (1999) classifica que uma frenagem ideal acontece quando a desaceleração produzida se aproxima do coeficiente de atrito estático do pneu no pavimento, se a desaceleração produzida ultrapassar o atrito estático disponível, o veículo irá travar as rodas e consequentemente o atrito entre pneu e o pavimento deixa de ser estático e passa a ser dinâmico, situação em que ocorre escorregamento, causando perda de estabilidade do carro. A distância de parada do carro irá aumentar pois o atrito dinâmico 
é inferior ao atrito estático. Nesse sentido, torna-se importante a elaboração de uma metodologia de ajuste do balance bar capaz de promover as condições ideais de frenagem descritas anteriormente.

Existe na literatura diferentes metodologias disponíveis e já consolidadas a serem usadas no projeto do sistema de freio de um veículo off-road. Por exemplo, Giansante (2017) elaborou uma metodologia de dimensionamento da pinça e disco de freio de um veículo off-road de competição com base na otimização dos esforços envolvidos durante a frenagem. Mais recentemente, Leonel Júnior e Guimarães (2019) também propuseram uma metodologia de projeto da pinça e disco de freio de um veículo off-road de competição usando análise de elementos finitos e otimização de topologia visando a minimização da massa do sistema e preservando sua integridade estrutural. Queiroz e Menezes (2014) propuseram uma metodologia de regulagem do balance bar baseado na análise do torque de frenagem requerido para o veículo de competição. Para isto, o sistema de freio foi regulado supondo que $70 \%$ da força aplicada pelo piloto ao pedal seja transferida para as rodas dianteiras e $30 \%$ para as rodas traseiras.

Neste trabalho, será proposta uma metodologia para o ajuste do balance bar de um veículo off-road em duas condições diferentes de frenagem. Na primeira condição, será suposto que $50 \%$ da força de frenagem seja aplicada as rodas dianteiras e os $50 \%$ para as rodas traseiras o que é considerado ideal para o veículo trafegando em pista de terra. $\mathrm{Na}$ segunda condição, o balance bar será ajustado para transferir $65 \%$ da força de frenagem para as rodas dianteiras, situação mais favorável para o veículo trafegando em asfalto. Nestas duas condições a máxima desaceleração permitida para o veículo será de $0,7 \mathrm{~g}$. Ao final será também feita a medição das forças de frenagem envolvidas a fim de se validar a metodologia proposta usando células de carga fixos no pedal e manômetros localizados na linha para a estimação da pressão usada no sistema.

\section{MATERIAIS E METODOS}

A primeira etapa no dimensionamento do sistema de freios do veículo off-road a ser considerado neste trabalho será encontrar o seu centro de gravidade. Devido aos amortecedores do veículo serem do tipo pneumático, é possível regular sua rigidez, com o objetivo de fixar as suspensões como recomenda a metodologia. Para tanto foi utilizada a pressão máxima dos amortecedores com o intuito de minimizar a deformação provocada pelos carregamentos. Para levantar a traseira e não gerar esforços horizontais, foram 
utilizados dois suportes de alturas diferentes e comparados os resultados obtidos da altura do centro de gravidade.

O teste foi dividido em duas etapas, com o piloto e sem o piloto, com o objetivo de comparar o deslocamento da altura e distância do centro de gravidade. Porém, no dimensionamento devem ser utilizados os parâmetros do centro de gravidade com o piloto. A Erro! Fonte de referência não encontrada.1 representa o esquema de montagem para o experimento e as variáveis que foram utilizadas.

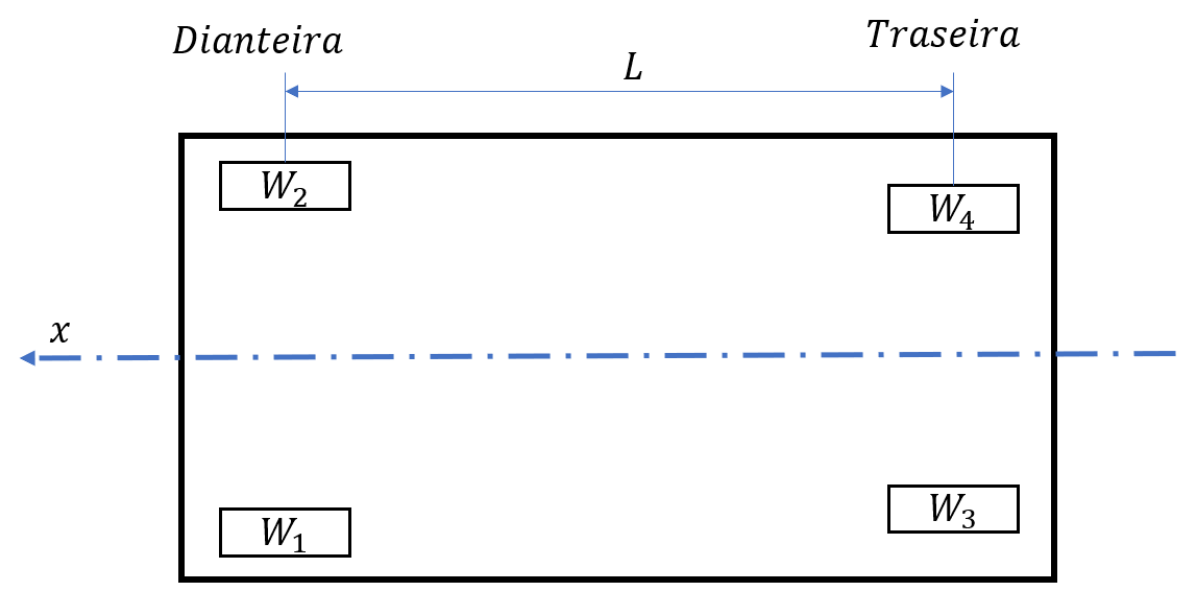

Figura 1. Esquema da vista superior do veículo para determinar seu centro de gravidade.

Para cada teste, foram realizadas 4 medições do peso e calculada a média entre elas. De acordo com a Fig. $8, W_{1}, W_{2}, W_{3}$ e $W_{4}$ representam as massas aferidas pela balança em cada uma das rodas do veículo. A soma de $W_{1}$ e $W_{2}$ resulta na carga estática do eixo dianteiro $\left(F z_{d}\right)$ e similarmente a soma de $W_{3}$ e $W_{4}$ resulta na carga estática do eixo traseiro $\left(F z_{t}\right)$, ambos apresentados na Fig. 1. Desta forma, foi possível encontrar a massa do carro com e sem o piloto.

Após medir o valor da distância entre eixos, $L$, foi possível encontrar a distância do centro de gravidade ao eixo dianteiro, $c$. Para encontrar a posição do centro de gravidade na direção $x$, que corresponde à distância do centro de gravidade ao eixo dianteiro, foi necessário levantar a traseira do protótipo em uma altura conhecida, para este caso, foi utilizado um suporte de altura $h_{\text {suporte_ }}=425 \mathrm{~mm}$ e outro suporte de altura $h_{\text {suporte_2 }}=740 \mathrm{~mm}$ e novamente realizar as medições dos pesos nas rodas dianteiras.

Um dos maiores desafios ao dimensionar o sistema de freios do veículo off-road é satisfazer a condição imposta pelo regulamento técnico da competição em que o veículo 
deve ser capaz de travar as 4 rodas. Com base nesse objetivo, foram elencadas as seguintes metas para o veículo:

- Travar as 4 rodas em até 5 metros com uma velocidade de $30 \mathrm{~km} / \mathrm{h}$;

- Aumentar a distribuição da força de frenagem dianteira acima de $65 \%$;

- Garantir o não travamento prematuro do eixo traseiro;

- Reduzir a força exercida pelo piloto no pedal em 35\%, a fim de fornecer uma desaceleração de $0,7 \mathrm{~g}$;

- Aumentar o curso do pedal em $100 \%$.

É necessário ressaltar a importância dos coeficientes de atrito utilizados nessa etapa, o mais crítico que gera mais incertezas é o atrito entre o disco e a pastilha, pois este varia com a temperatura do disco, qualidade das pastilhas e material do disco. Foi utilizado neste trabalho um valor intermediário do recomendado para pastilhas fabricadas em material semimetálico, 0,35 a 0,45 (LIMPERT, 1999). Em relação ao atrito entre o pneu e o solo, para a terra batida foi utilizado o coeficiente de atrito de 0,67 obtido através de testes, e para o asfalto foi utilizado o coeficiente de atrito de 0,95 conforme recomendado por Nicolazzi, Leal e Rosa (2012).

A Tabela 1 descreve alguns parâmetros geométricos do veículo, bem como, o peso total necessário para cálculo das forças envolvidas durante a frenagem. Já a Tabela 2 fornece os dados do sistema hidráulico usado pelo sistema de frenagem do veículo também necessários para a validação experimental dos testes a serem realizados.

Tabela 1. Parâmetros estáticos do veículo off-road.

\begin{tabular}{ccc}
\hline Denominação & Parâmetro & Magnitude \\
\hline Peso & $W$ & $2791,44 \mathrm{~N}$ \\
Entre Eixos & $L$ & $1400 \mathrm{~mm}$ \\
Distância do eixo dianteiro ao CG & $C$ & $833,75 \mathrm{~mm}$ \\
Altura do CG & $h$ & $560,00 \mathrm{~mm}$ \\
Raio do pneu dianteiro & $R_{d}$ & $266 \mathrm{~mm}$ \\
Raio do pneu traseiro & $R_{t}$ & $266 \mathrm{~mm}$ \\
\hline
\end{tabular}


Tabela 2. Dados do sistema hidráulico do sistema de frenagem.

\begin{tabular}{ccc}
\hline Denominação & Parâmetro & Magnitude \\
\hline & Dianteiro \\
\hline Área do cilindro mestre & $A_{c m, d}$ & $1,267 \mathrm{~cm}^{2}$ \\
Área da pinça & $A_{p, d}$ & $7,135 \mathrm{~cm}^{2}$ \\
Raio do disco & $r_{\text {disco,d }}$ & $65 \mathrm{~mm}$ \\
Quantidade de pinças & $N_{d}$ & 2 \\
\hline Área do cilindro mestre & $A_{c m, t}$ & $1,267 \mathrm{~cm}^{2}$ \\
Área da pinça & $A_{p, t}$ & $7,135 \mathrm{~cm}^{2}$ \\
Raio do disco & $r_{d i s c o, t}$ & $75 \mathrm{~mm}$ \\
Quantidade de pinças & $N_{t}$ & 1 \\
\hline
\end{tabular}

Para a medição das forças foram utilizadas células de carga fixadas no pedal. A ideia de adquirir a força exercida no pedal partiu da necessidade de realizar testes experimentais no sistema de freios de forma a validar a metodologia teórica descrita anteriormente. As adotadas nesse trabalho utilizam extensômetros colados na superfície da célula, e ao exercer uma força sobre a superfície, a célula deforma provocando uma variação de resistência nos extensômetros.

Levando em consideração a necessidade de utilizar uma célula de carga colada no pedal de freio, que a força no pedal exercida pelo piloto não é controlada e que o sistema deve ser de baixo custo e compacto, foram utilizadas duas células de carga com capacidade máxima $50 \mathrm{~kg}$ cada, um módulo HX711 que tem a função de amplificar o sinal de saída da célula e um microcontrolador Arduino Uno. A Erro! Fonte de referência não encontrada. 2 apresenta o esquema de montagem dos componentes.

Antes de se obter a força exercida sobre as células de carga foi necessário encontrar a sensibilidade das células e assim implementar o fator de sensibilidade no código que fará a aquisição da força exercida. Para a aquisição da sensibilidade foi utilizado a biblioteca do módulo HX711.h do Arduino®.

Os materiais utilizados neste teste foram:

- 4 Corpos de prova de $1 \mathrm{~kg}$;

- 2 Corpos de prova de 1,4kg;

- 1 Corpo de prova de 1,25kg. 


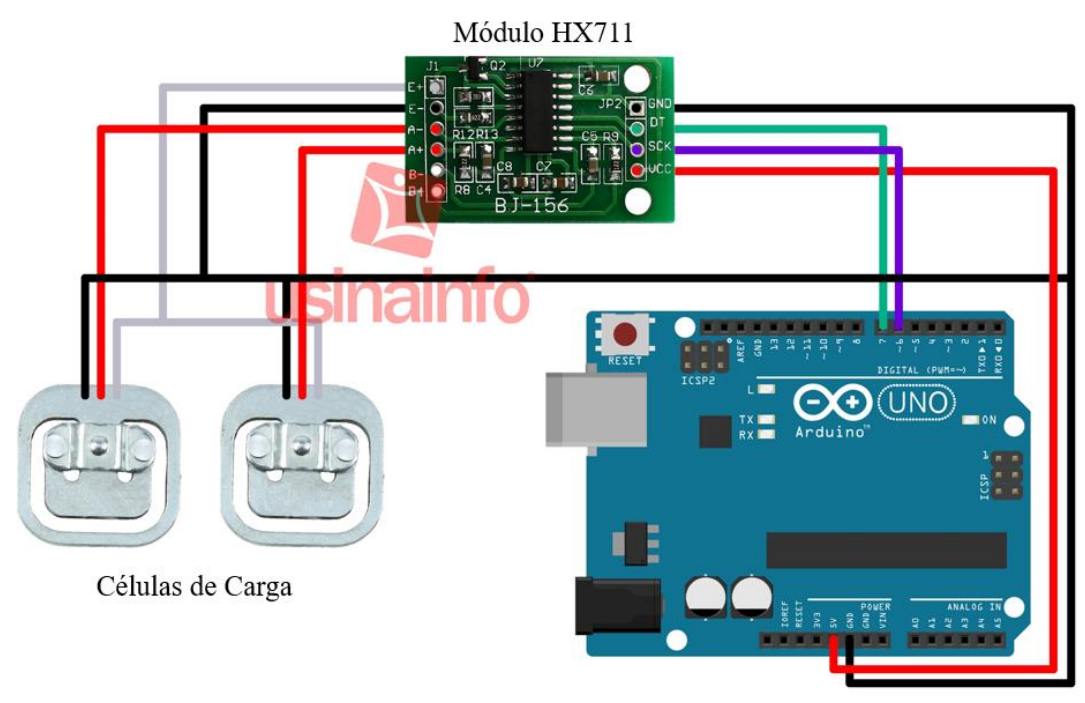

Figura 2. Instrumentação usada na medição das forças aplicadas no pedal (adaptado de Blog Usinainfo, 2017).

Foram realizados 2 testes para cada combinação das massas conhecidas afim de analisar se para diferentes massas a sensibilidade se mantém constante, ou seja, se a leitura feita pelo Arduino aumenta linearmente.

A primeira combinação das massas consistiu em adicionar sobre a célula de carga $1 \mathrm{~kg}$ a cada 30 segundos, totalizando $4 \mathrm{~kg}$. E a segunda combinação foi colocado $2 \mathrm{~kg}, 2 \mathrm{~kg}$, $2,8 \mathrm{~kg}$ e por fim $1,25 \mathrm{~kg}$, totalizando $8,05 \mathrm{~kg}$. O código foi configurado para realizar a leitura a cada 0,5 segundos, portanto a cada 30 segundos foram adquiridas 60 leituras. As 10 primeiras e 10 últimas leituras antes e depois de adicionar cada massa foram desconsiderados, pois os corpos de provas foram adicionados sobre a célula de carga com a mão, o que gera uma certa instabilidade das leituras até o corpo de prova equilibrar sobre a célula.

Além da medição das forças com células de carga foi realizada também a medição da pressão da linha do sistema hidráulico com manômetros conectados ao sistema. De acordo com o dimensionamento teórico, há duas configurações no balance bar necessárias, quando distribui a força igualmente entre os cilindros mestres (50\% - 50\%) sendo o ajuste mais adequado ao trafegar em terra batida e o ajuste de $65 \%$ da força para o cilindro mestre dianteiro e 35\% para o traseiro, configuração ótima ao trafegar no asfalto.

A Erro! Fonte de referência não encontrada. 3 apresenta o esquema que foi utilizado neste teste. Foi necessário utilizar a célula de carga calibrada para adquirir a força que o piloto exerce no pedal e dois manômetros que foram conectados em cada linha após os cilindros de freio. 


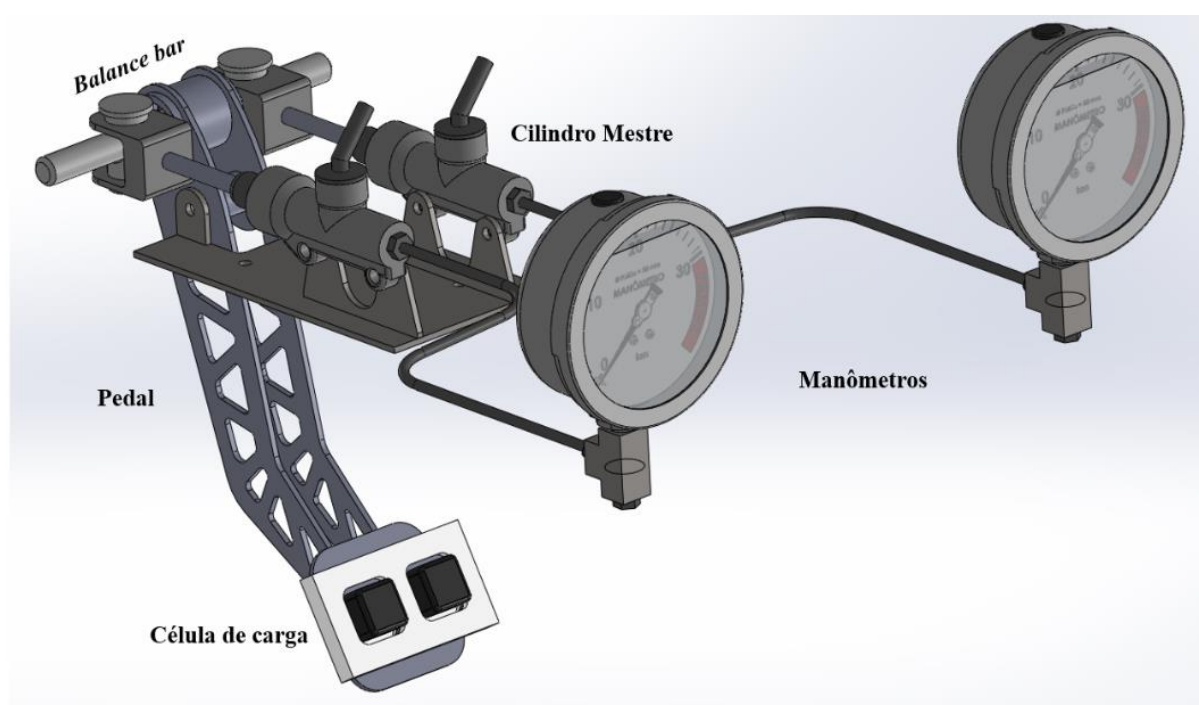

Figura 3. Instrumentação usada na medição da pressão empregada no sistema hidráulico.

\section{RESULTADOS}

Após a definição do Centro de Gravidade do veículo e a distribuição de carga estática, foi realizado o dimensionamento do sistema de frenagem. Como estratégia de dimensionamento, foi utilizado a combinação mais simples e segura para o balance bar de $50 \%-50 \%$ para garantir as metas do Sistema. Após atingí-las, o ajuste foi configurado para garantir uma frenagem segura e com maior eficiência no asfalto. Este novo sistema também proporcionou projetar um novo pedal, tendo como vantagem aumentar a relação de alavanca, consequentemente, reduzindo a força exercida pelo piloto para produzir a pressão necessária.

Os resultados apresentados na Fig. 4 foram calculados utilizando a configuração no balance bar de $50 \%$ - 50\% e $65 \%$ - 35\% de distribuição da força de frenagem para cada eixo. Como parâmetro de entrada para os cálculos, foi utilizado a força exercida pelo piloto no pedal de freio variando de 0 a $600 \mathrm{~N}$ com $50 \mathrm{~N}$ de incremento, tornando-se possível obter o gráfico da Fig. 4. A pressão nas linhas de freio traseira e dianteira, o torque resultante, a desaceleração, a carga dinâmica e força ótima de frenagem foram calculados utilizando as equações disponíveis na literatura (LIMPERT, 1999).

Na Tabela 3 são mostrados os valores dos parâmetros de pressão na linha, torque resultante e força de frenagem, calculados para o sistema de frenagem a partir da força no pedal para a distribuição de $50 \%$ - 50\%. 


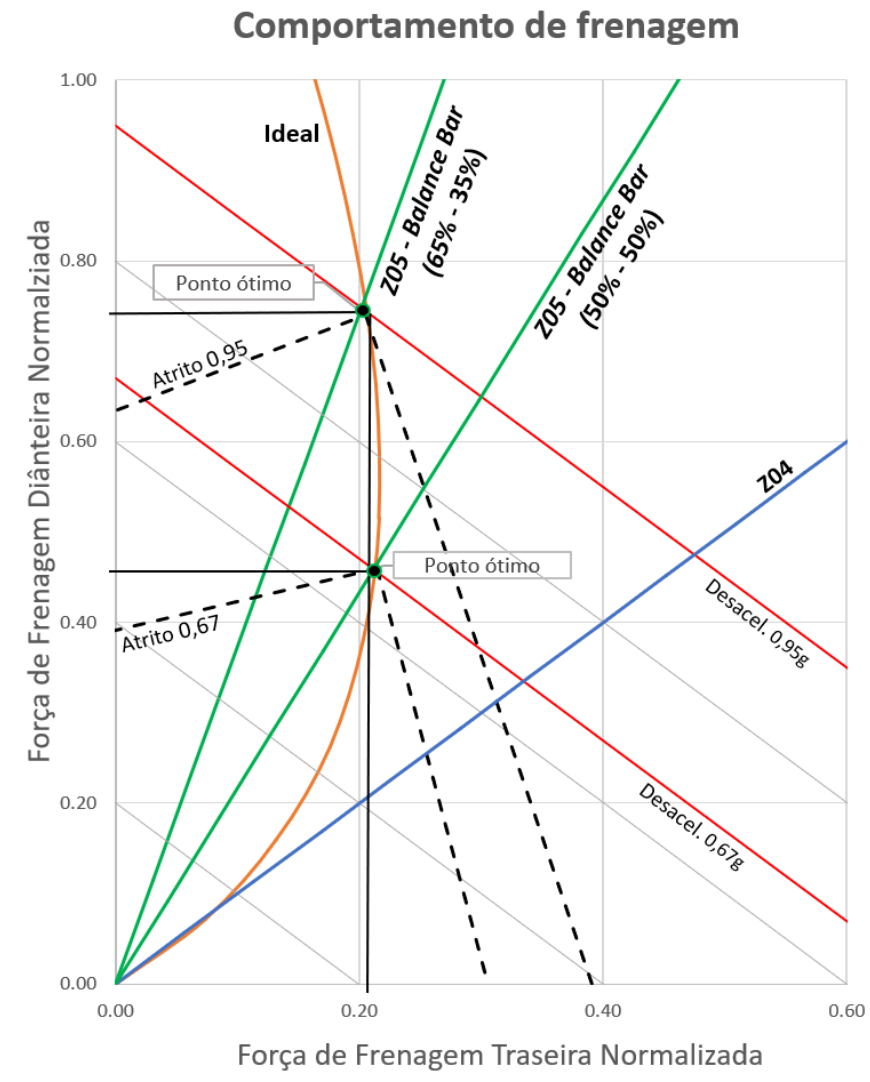

Figura 4. Comportamento de frenagem do veículo para as configurações do balance bar de $50 \%-50 \%$ e $65 \%-35 \%$.

Tabela 3. Pressão, torque resultante e força de frenagem, calculados em função da força aplicada no pedal para o ajuste do balance bar de 50\% - 50\%.

\begin{tabular}{cccccccc}
\hline \multirow{2}{*}{$\begin{array}{c}\text { Força no } \\
\text { Pedal [N] }\end{array}$} & \multicolumn{2}{c}{ Pressão na linha [N/cm $\left.\mathbf{c}^{2}\right]$} & \multicolumn{2}{c}{ Torque resultante [N.m] } & \multicolumn{3}{c}{ Força de frenagem [N] } \\
\cline { 2 - 7 } & Traseiro & Dianteiro & Traseiro & Dianteiro & Traseiro & Dianteiro & Total \\
\cline { 2 - 7 } 0,0 & 0,00 & 0,00 & 0,00 & 0,00 & 0,00 & 0,00 & 0,00 \\
50,0 & 78,94 & 78,94 & 16,82 & 34,12 & 124,50 & 215,80 & 340,30 \\
100,0 & 157,88 & 157,88 & 33,63 & 68,24 & 249,00 & 431,61 & 680,61 \\
150,0 & 236,82 & 236,82 & 50,45 & 102,37 & 373,50 & 647,41 & 1020,91 \\
200,0 & 315,76 & 315,76 & 67,26 & 136,49 & 498,01 & 863,21 & 1361,22 \\
250,0 & 394,71 & 394,71 & 84,08 & 170,61 & 622,51 & 1079,01 & 1701,52 \\
300,0 & 473,65 & 473,65 & 100,90 & 204,73 & 747,01 & 1294,82 & 2041,83 \\
350,0 & 552,59 & 552,59 & 117,71 & 238,85 & 871,51 & 1510,62 & 2382,13 \\
400,0 & 631,53 & 631,53 & 134,53 & 272,98 & 996,01 & 1726,42 & 2722,43 \\
450,0 & 710,47 & 710,47 & 151,35 & 307,10 & 1120,51 & 1942,22 & 3062,74 \\
500,0 & 789,41 & 789,41 & 168,16 & 341,22 & 1245,02 & 2158,03 & 3403,04 \\
550,0 & 868,35 & 868,35 & 184,98 & 375,34 & 1369,52 & 2373,83 & 3743,35 \\
600,0 & 947,29 & 947,29 & 201,79 & 409,46 & 1494,02 & 2589,63 & 4083,65 \\
\hline
\end{tabular}


Na Tabela 4 são mostrados os valores dos parâmetros desaceleração, carga dinâmica e força ótima de frenagem, calculados a partir da força exercida pelo piloto no pedal de freio variando de 0 a $600 \mathrm{~N}$ com $50 \mathrm{~N}$ de incremento, para o sistema de frenagem a partir da força no pedal para a distribuição de 50\% - 50\%.

Tabela 4. Desaceleração, carga dinâmica e força ótima de frenagem, calculados em função da força aplicada no pedal para o ajuste do balance bar de 50\% - 50\%.

\begin{tabular}{cccccc}
\hline \multirow{2}{*}{$\begin{array}{c}\text { Força no } \\
\text { Pedal [N] }\end{array}$} & Desaceleração [g] & \multicolumn{2}{c}{ Carga Dinâmica [N] } & \multicolumn{2}{c}{ Força ótima de frenagem [N] } \\
\cline { 2 - 6 } 0,00 & 0,00 & 1662,55 & 1128,89 & 0,00 & 0,00 \\
50,0 & 0,12 & 1526,43 & 1265,01 & 186,09 & 154,22 \\
100,0 & 0,24 & 1390,31 & 1401,13 & 338,98 & 341,62 \\
150,0 & 0,37 & 1254,18 & 1537,25 & 458,69 & 562,22 \\
200,0 & 0,49 & 1118,06 & 1673,37 & 545,21 & 816,00 \\
250,0 & 0,61 & 981,94 & 1809,49 & 598,54 & 1102,98 \\
300,0 & 0,73 & 845,82 & 1945,62 & 618,68 & 1423,14 \\
350,0 & 0,85 & 709,70 & 2081,74 & 605,64 & 1776,49 \\
400,0 & 0,98 & 573,58 & 2217,86 & 559,40 & 2163,04 \\
450,0 & 1,10 & 437,45 & 2353,98 & 479,97 & 2582,77 \\
500,0 & 1,22 & 301,33 & 2490,10 & 367,36 & 3035,69 \\
550,0 & 1,34 & 165,21 & 2626,22 & 221,55 & 3521,80 \\
600,0 & 1,46 & 29,09 & 2762,35 & 42,56 & 4041,10 \\
\hline
\end{tabular}

O gráfico da Erro! Fonte de referência não encontrada.5 foi obtido a partir das cargas dinâmica e desaceleração. A partir deste é possível verificar o fenômeno chamado transferência de carga ao frear o veículo, quando o eixo traseiro transfere carga para o eixo dianteiro conforme aumenta a desaceleração, resultando na sensação que o eixo traseiro fica mais leve. 


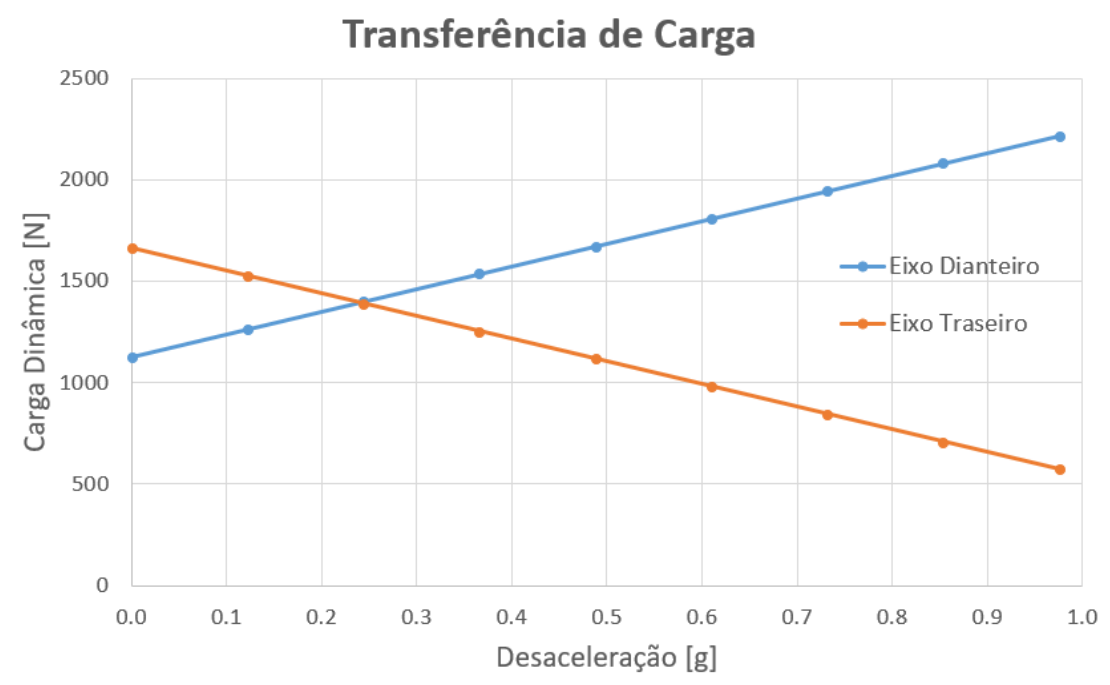

Figura 5. Transferência de carga do eixo traseiro para o eixo dianteiro durante a frenagem.

Conforme mencionado anteriormente, o ponto ideal é a intersecção das linhas de atrito, desaceleração e curva ideal de frenagem. Em terra batida, o ponto ideal pode ser verificado na Erro! Fonte de referência não encontrada.6.

Região de travamento dos eixos

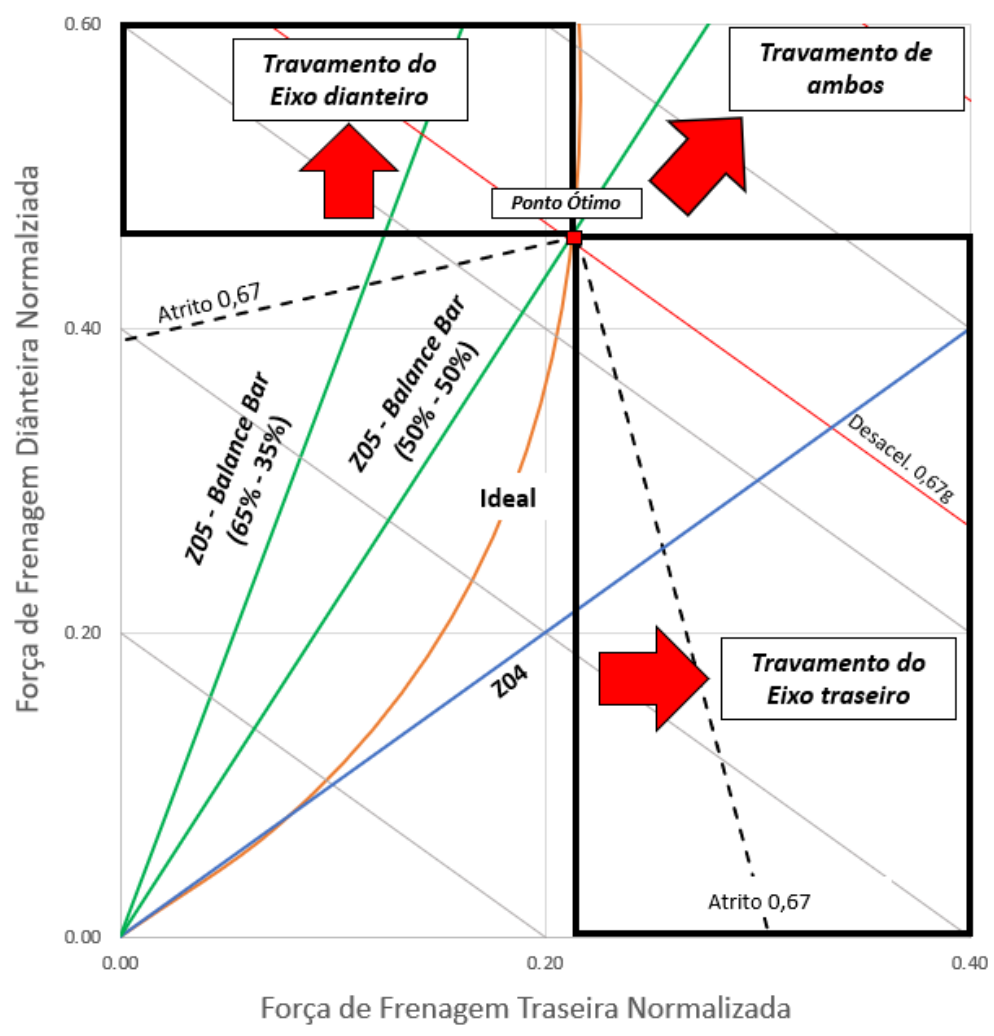

Figura 6. Representação das regiões de travamento dos eixos em terra batida. 
Ao avaliar a força de frenagem normalizada do eixo dianteiro, o travamento do eixo ocorre na região ao lado esquerdo da curva ideal e acima de 0,47 (ponto ótimo), no caso do eixo traseiro, seu travamento ocorre ao lado direito da curva ideal e acima de 0,21 (ponto ótimo) e a região acima do ponto ótimo tanto para a força de frenagem no eixo dianteiro como no eixo traseiro corresponde ao travamento de ambos.

A fim de se validar os resultados teóricos, por último foi realizada a medição experimental das forças e pressões envolvidas na frenagem usando a metodologia descrita anteriormente. A partir do que foi apresentado neste item, os ensaios foram realizados e os valores obtidos através do Arduino foram usados para plotar os gráficos mostrados nas Figuras 7, 8 e 9 para as diferentes combinações das massas utilizadas sobre a célula de carga.

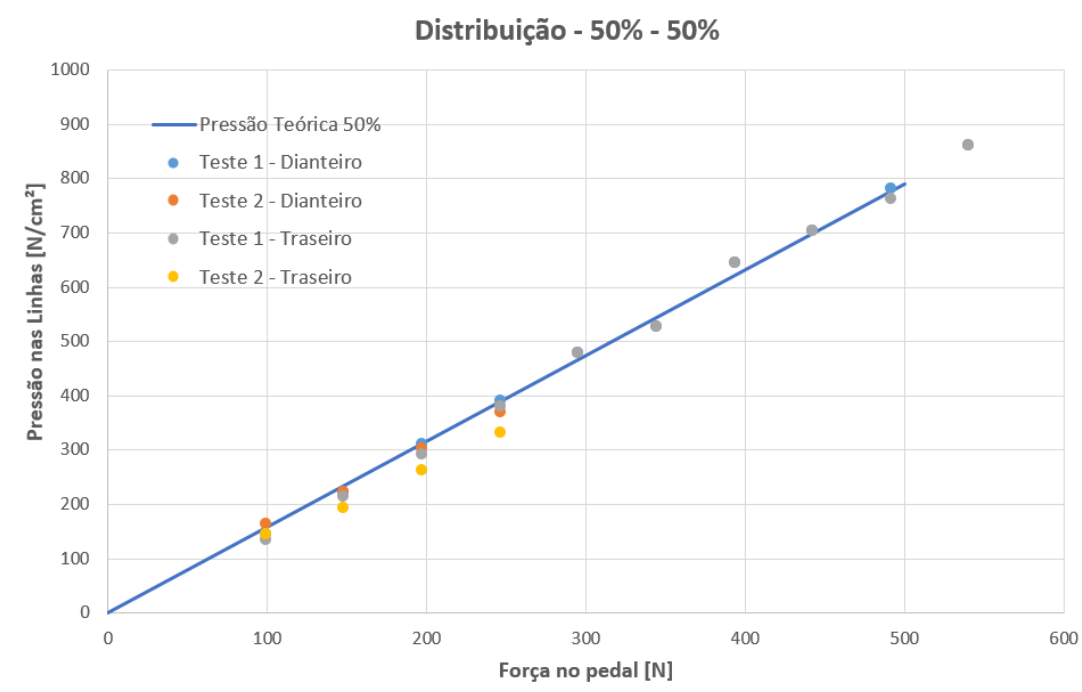

Figura 7. Pressão teórica e experimental para a distribuição de 50\% - 50\% no balance bar.

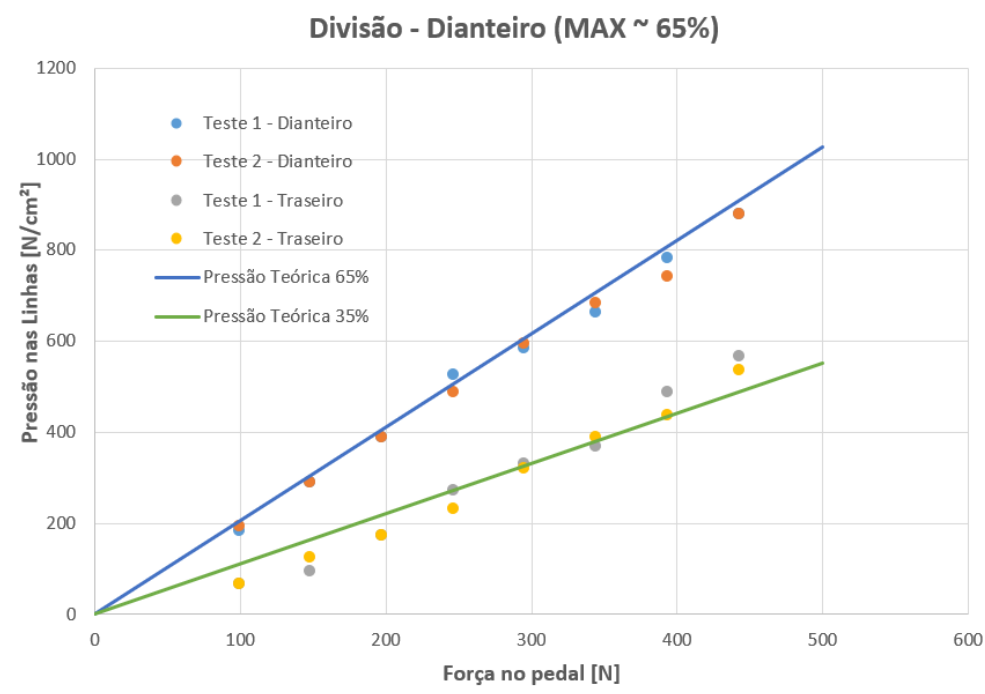

Figura 8. Pressão teórica e experimental para a distribuição de $65 \%$ no eixo dianteiro. 


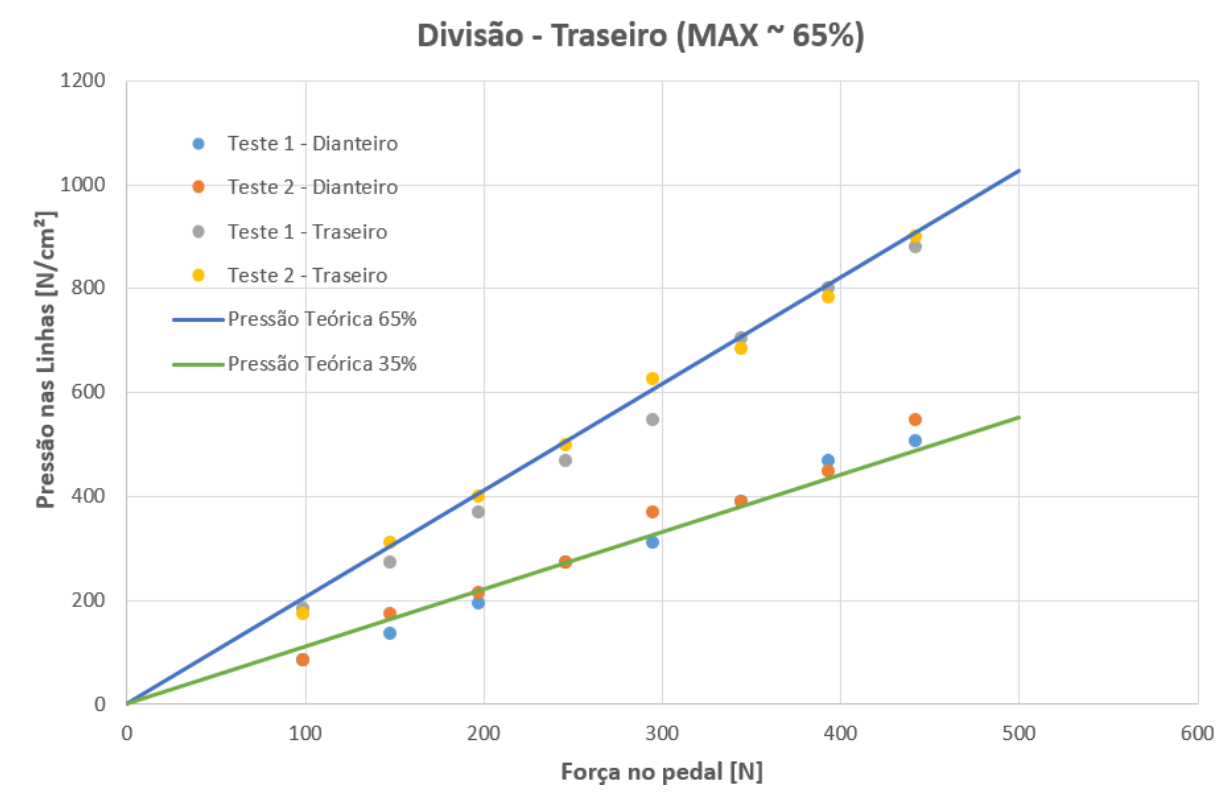

Figura 9. Pressão teórica e experimental para a distribuição de 65\% no eixo traseiro.

\section{DISCUSSÃO}

No dimensionamento do sistema de frenagem, os parâmetros de entradas apresentados nas tabelas anteriores foram inseridos nas equações previstas na teoria (LIMPERT, 1999), verificando-se que a relação do pedal com valor igual a 5,0 atingia resultados satisfatórios, porém a linha de frenagem real ainda não cruzava exatamente no ponto ótimo mostrado na Fig. 4. Conforme mostrado na Fig. 4, o ponto ótimo de frenagem ocorre quando a força de frenagem nas rodas dianteiras e traseiras se igualam a força de desaceleração de $0,67 \mathrm{~g}$ e $0,95 \mathrm{~g}$ para a condição de asfalto $(50 \%$ e $50 \%)$ e pista de terra (65\% e $35 \%$ ). Pensando nisso e na nova necessidade de projetar um novo disco de freio traseiro, este que seria acoplado na saída da caixa de redução, houve um acréscimo de $10 \mathrm{~mm}$ em relação ao disco de freio dianteiro, resultando em disco de raio efetivo de $75 \mathrm{~mm}$, o que permitiu realizar o ajuste da linha real de frenagem exatamente no ponto ótimo (Erro! Fonte de referência não encontrada.4). A linha correspondente ao rótulo Z04 equivale ao projeto do veículo off-road antigo e as linhas Z05 do veículo off-road a ser otimizado.

Ao avaliar os gráficos das Figuras 7, 8 e 9, mesmo para os diferentes ajustes do balance bar, os valores medidos nos ensaios utilizando os manômetros e a célula de carga estão próximos e seguem a tendência dos valores teóricos que foram calculados previamente durante a etapa de projeto. Uma dificuldade encontrada durante os testes foi evitar os pequenos vazamentos das conexões em " $T$ " que foram ligadas aos manômetros, mesmo 
tentando retirar todo 0 ar das linhas de freio (sangrar) estes pequenos vazamentos permitiam que algum ar permanece nas linhas.

Outra dificuldade encontrada durante os testes foi manter a força no pedal estável no instante de adquirir as pressões nas linhas, principalmente quando a força excedia $30 \mathrm{kgf}$. Tornando-se ideal a utilização de transdutor de pressão, o que possibilitaria adquirir digitalmente as pressões e assim poder avaliar a pressão $x$ força continuamente, não necessitando estabilizar a força no pedal para adquirir a pressão com o manômetro.

\section{CONSIDERAÇOES FINAIS}

Neste trabalho foi proposta uma metodologia de projeto de um sistema de frenagem de um veículo off-road de competição. Para validação da metodologia, os resultados teóricos também foram validados experimentalmente por meio da medição da força e pressão empregados durante a frenagem usando células de carga e manômetros instalados no sistema. O objetivo geral do projeto de conforto e confiabilidade foi atingido e permitiu que as metas que foram estabelecidas para o sistema de freios estivessem de acordo com o projeto.

Com a obtenção do Centro de Gravidade do veículo de forma experimental foi possível dimensionar os componentes como pedal, disco e balance bar. A combinação de um novo projeto para esses 3 componentes permitiu que as metas impostas fossem alcançadas, 0 aumento da relação do pedal, que no projeto anterior possuía valor igual a 4,5, para o valor de 5,0 permitiu reduzir a força no pedal em mais de $35 \%$ em relação ao projeto anterior. Assim, com o ajuste no raio efetivo do disco traseiro de $65 \mathrm{~mm}$ para $75 \mathrm{~mm}$ e a utilização dos ajustes disponíveis do balance bar, $50 \%-50 \%$ e $65 \%$ - 35\%, permitiram ao projeto o não travamento prematuro do eixo traseiro, mais do que isso, foi o ajuste exatamente no ponto ideal. Como mencionado ao longo do trabalho, o ajuste do sistema nesse ponto permite a maior eficiência durante a frenagem do veículo.

A contribuição em mais de $65 \%$ da força de frenagem para o eixo dianteiro foi importante tanto para atingir as metas quanto no trabalho em conjunto com o sistema de suspensão no controle do anti-dive do veículo, reforçando os ganhos que o sistema de freios obteve com o novo projeto de balance bar.

A ideia de construir um sistema de aquisição com células de carga foi muito importante para atingir o objetivo de confiabilidade do sistema, pois possibilitou comprovar através dos ensaios realizados que o sistema de balance bar possui a sua funcionalidade esperada, além de ter permitido comparar os valores de força x pressão real com o teórico. Do ponto 
de vista do sistema de freios, pode-se concluir que este trabalho contribuiu para seu melhor entendimento e busca por soluções vivenciadas pelo sistema ao longo das competições.

A fim de aperfeiçoar o sistema de medição da força exercida no pedal e da pressão da linha do sistema de frenagem, bem como, a previsão teórica da força de frenagem, são propostas as seguintes sugestões para trabalhos futuros:

- Utilização de conexões, da linha de freio para os manômetros, que impossibilitem o vazamento de ar e facilite a medição da pressão;

- Obtenção de um coeficiente de atrito entre o disco e a pastilha de freio mais realista, levando em conta o efeito da temperatura;

- Elaboração de um dispositivo que permita que a força exercida no pedal seja constante e sem variações ao longo de todo o ensaio.

\section{REFERÉNCIAS}

Sensor de peso com Arduino - A variação de um strain gauge., 2017. Disponível em: <http://blog.usinainfo.com.br/sensor-de-peso-com-arduino-variacao-de-um-strain-gage/> (Acesso em: 30 de junho de 2018).

CAMPBELL, C. The sports car. Its design and performance, 3rd ed.; Chapman and Hall Ltd. 1970.

COSTA NETO, A. Dinâmica veicular. São Carlos: Departamento de de Materiais, Aeronáutica e Automobilística, Escola de Engenharia de São Carlos, USP.2006.

GIANSANTE, B. C. Z. Desenvolvimento de um sistema de freio para veículo off-road leve de competição BAJA SAE. Monografia de projeto final de curso de graduação em engenharia mecânica, UFRJ, 62 p. 2017.

LEONEL JÚNIOR, W. S; GUIMARÃES, T. A. Finite Element Analysis and Topology Optimization of the Brake Caliper and its Supports. $25^{\text {th }}$ ABCM International Congress of Mechanical Engineering (COBEM 2019), Uberlândia, Brasil. 2019.

LIMPERT, R. Brake Design and Safety. 2ªed., SAE International.1999.

MORTIMER, R. G. et al., Brake Force Requirement Study: Driver - Vehicle Braking Performance as a Function of Brake System Design Variable. Ann Arbor: Highway Safety Research Institute, University of Michigan, 200 p.1970.

NICOLAZZI, L. C.; LEAL, L. C. M.; ROSA, E. Uma Introdução à modelagem quase estática de veículos automotores de rodas. Florianópolis: Departamento de Engenharia Mecânica, UFSC, Publicação interna do GRANTE.2008.

QUEIROZ, J. R. S.; MENEZES, M. A. Método de regulagem de um sistema de freio via balance bar. XXVI Congresso de Iniciação Científica da UNESP, Ilha Solteira: Engenharia Mecânica, UNESP.2014. 